\title{
Synthetic
}

\section{hydroxyapatite orbital implants: a clinical and MRI evaluation}

\begin{abstract}
Purpose Coralline hydroxyapatite orbital implants have been used since the 1980s. More recently, synthetic hydroxyapatite orbital implants have been used, in both primary and secondary orbital implantation surgery. The implant may be drilled and pegged, if required, after adequate vascularisation of the implant has occurred. In this study we evaluated the clinical results and vascularisation of synthetic hydroxyapatite orbital implants.

Methods Twelve consecutive patients who had synthetic hydroxyapaptite orbital implants were evaluated clinically and 8 of these patients had orbital magnetic resonance imaging (MRI) scans with intravenous gadolinium performed at least 9 months postoperatively to assess vascularisation of the implant. Six patients had primary orbital implants at the time of enucleation and 6 patients had secondary implants.

Results No significant complications occurred following insertion of the synthetic hydroxyapatite orbital implants. All patients reported cosmetic satisfaction with the results of surgery. MRI scans revealed inhomogeneous enhancement in 3 of the 4 patients receiving primary implants. All patients with secondary implants and 1 patient who had a primary implant had moderate to large areas of poor enhancement in the implant.

Conclusion Synthetic hydroxyapatite implants gave good clinical results but variable vascularisation occurs, especially with secondary implants.
\end{abstract}

Key words Clinical evaluation, Hydroxyapatite orbital implants, MRI

Following enucleation, an intraorbital implant provides good volume augmentation and improves the range of movement of the ocular prosthesis. Orbital implants have been made from a variety of materials. Complications such as inflammation, infection, exposure and extrusion may, however, occur. ${ }^{1}$
Hydroxyapatite derived from coral has been used in bone and maxillofacial reconstructive surgery. In 1989 its use as an orbital implant was approved by the American Food and Drug Administration. ${ }^{2}$ These implants become vascularised and are very stable in the orbit. They may be drilled and pegged to allow better mobility and support of the artificial eye. ${ }^{2,3}$ Synthetic orbital hydroxyapatite implants (manufactured by FCI, France) have more recently become available. They are less expensive than coral implants and are advertised as being as good. Synthetic orbital hydroxyapatite implants are made of biocompatible, non-toxic material with interconnecting pores $900-1100 \mu \mathrm{m}$ in diameter. These pores allow fibrovascular ingrowth. FCI claims that vascularisation of these implants occurs in 4-6 months. When vascularisation has occurred, implants may be drilled and pegged like the coral implants.

Histopathology, ${ }^{4}$ technetium isotope scanning, ${ }^{5,6}$ computed tomography ${ }^{6}$ and magnetic resonance imaging (MRI $)^{6,7}$ have been used to demonstrate fibrovascular ingrowth in orbital hydroxyapatite implants. MRI with intravenous gadolinium is thought to provide the most accurate non-invasive estimate of vascularisation of the implant. ${ }^{6}$

We report the clinical and MRI results of a series of consecutive patients who underwent either primary or secondary synthetic hydroxyapatite orbital implantation.

\section{Method}

Twelve consecutive patients who had synthetic (FCI) hydroxyapatite spheres ranging in diameter between 16 and $22 \mathrm{~mm}$ implanted in 1995 were evaluated at least 9 months after implantation. The indications for implantation and ages of these patients are detailed in Table 1. Surgery was performed by one surgeon (G.T.F.).

The surgical technique for insertion of hydroxyapatite implants has been described previously. ${ }^{1}$ Some aspects deserve special mention. During insertion the implant was covered with plastic, which allowed the implant
N. Sarvananthan

G.T. Fahy

Department of

Ophthalmology

Leicester Royal Infirmary Leicester LE1 5WW, UK

\section{A.J. Liddicoat}

Department of Radiology Leicester Royal Infirmary Leicester LE1 5WW, UK

Gerry T. Fahy, MD, FRCS, FRCOphth

Leicester Royal Infirmary Infirmary Square Leicester LE1 5WW, UK

Tel: +44 (0)116 2586716 Fax: +44 (0)1162585927

Received: 22 June 1998 Accepted in revised form: 11 December 1998 
Table 1. Clinical data including indications for enucleation, timing of surgery and MRI results for synthetic (FCI) hydroxyapatite orbital implantation surgery

\begin{tabular}{|c|c|c|c|c|c|c|}
\hline $\begin{array}{c}\text { Age } \\
\text { (years) }\end{array}$ & Sex & Indication for enucleation & $\begin{array}{l}\text { Primary or } \\
\text { secondary implant }\end{array}$ & $\begin{array}{l}\text { Size of } \\
\text { implant } \\
(\mathrm{mm})\end{array}$ & $\begin{array}{l}\text { Time of MRI } \\
\text { (months } \\
\text { post-operatively) }\end{array}$ & Result of MRI \\
\hline 36 & $\mathrm{M}$ & Trauma. Blind painful eye & Primary & 22 & 13 & Diffuse inhomogeneous enhancement \\
\hline 71 & $\mathrm{M}$ & Phthisis bulbi & Primary & 20 & 12 & Diffuse inhomogeneous enhancement \\
\hline 27 & $\mathrm{~F}$ & Tuberculous endophthalmitis & Primary & 20 & 9 & $\begin{array}{l}\text { Enhancement in periphery but a large } \\
\text { area of poor non-enhancement } \\
\text { posteromedially }\end{array}$ \\
\hline 23 & $\mathrm{M}$ & Buphthalmos & Primary & 20 & 10 & Diffuse inhomogeneous enhancement \\
\hline 17 & $\mathrm{~F}$ & Microphthalmos & Primary & 20 & No scan & Did not attend \\
\hline 23 & $\mathrm{M}$ & Trauma. Blind, painful eye & Primary & 22 & No scan & Did not attend \\
\hline 5 & $\mathrm{~F}$ & Retinoblastoma & $\begin{array}{l}\text { Secondary ( } 4 \text { years } \\
\text { after enucleation) }\end{array}$ & 16 & 19 & Moderate area of non-enhancement \\
\hline 20 & $\mathrm{M}$ & Trauma. Blind, painful eye & $\begin{array}{l}\text { Secondary } \\
\text { (18 months after } \\
\text { enucleation) }\end{array}$ & 22 & 9 & $\begin{array}{l}\text { Large area of non-enhancement } \\
\text { centrally extending medially }\end{array}$ \\
\hline 34 & $\mathrm{~F}$ & Trauma. Blind eye & $\begin{array}{l}\text { Secondary ( } 23 \text { years } \\
\text { after enucleation) }\end{array}$ & 20 & 13 & $\begin{array}{l}\text { Large areas of non-enhancement } \\
\text { centrally with smaller areas in } \\
\text { periphery }\end{array}$ \\
\hline 52 & $\mathrm{~F}$ & Measles keratitis. Perforation & $\begin{array}{l}\text { Secondary ( } 50 \text { years } \\
\text { after enucleation) }\end{array}$ & 18 & 9 & $\begin{array}{l}\text { Large area of non-enhancement in the } \\
\text { periphery }\end{array}$ \\
\hline 44 & $\mathrm{~F}$ & Trauma. Blind eye & $\begin{array}{l}\text { Secondary ( } 6 \text { years } \\
\text { after enucleation) }\end{array}$ & 20 & No scan & Metal in orbit. MRI not performed \\
\hline 33 & $\mathrm{M}$ & Explosion injury. Perforation & $\begin{array}{l}\text { Secondary ( } 4 \text { years } \\
\text { after enucleation) }\end{array}$ & 20 & No scan & $\begin{array}{l}\text { Metal in orbit and sinus. MRI not } \\
\text { performed }\end{array}$ \\
\hline
\end{tabular}

to be inserted into the posterior orbit. ${ }^{1}$ The plastic covering was then removed. The anterior half of the synthetic hydroxyapatite orbital implant was covered with donor sclera and windows were made in the sclera for the attachment of the four recti muscles. Tenon's and conjunctival layers were closed separately without tension using 8.0 Vicryl. Intravenous antibiotics were administered at induction and oral antibiotics prescribed for 5 days post-operatively.

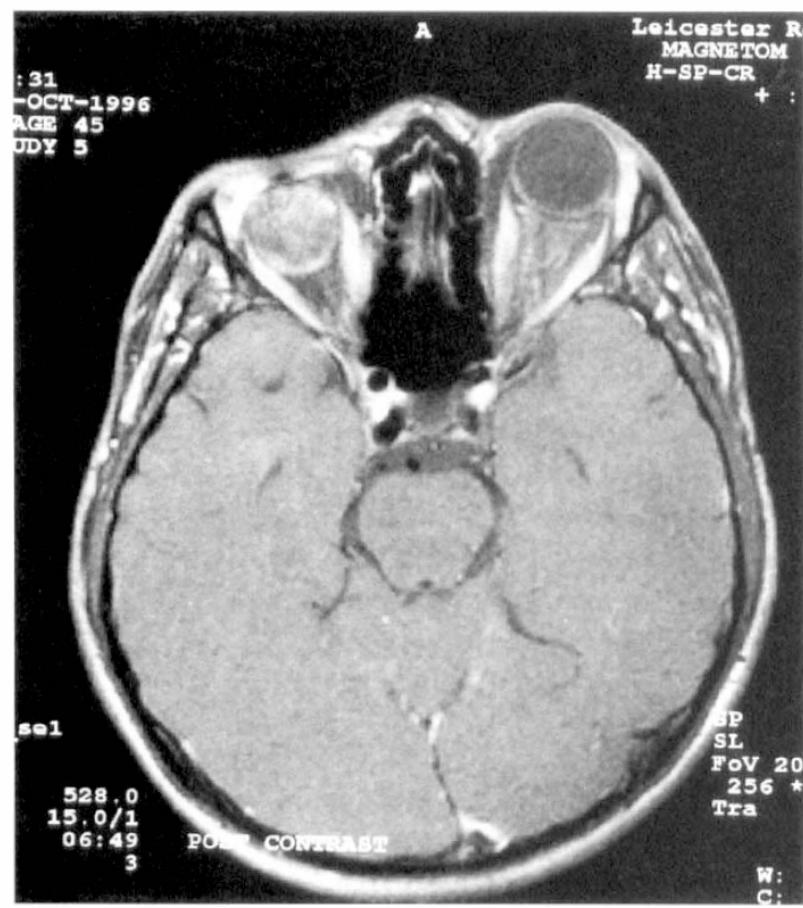

(a)
Patients were followed-up regularly. All patients had a clinical assessment at least 9 months after surgery. Patients were asked about their subjective impressions of the cosmetic result of surgery. MRI of the implant was performed at least 9 months after surgery using T1weighted fat-suppressed $3 \mathrm{~mm}$ scans performed through the orbits in the axial and coronal planes before and after intravenous injection of gadolinium $(0.2 \mathrm{mg} / \mathrm{kg})$. All scans were performed on a Siemens Magnetom 1.0 T

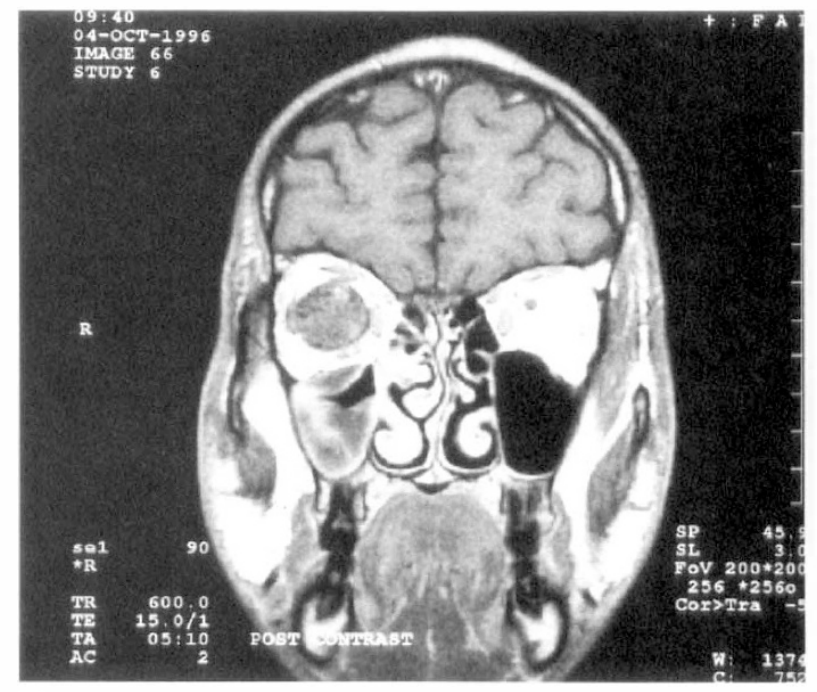

(b)

Fig. 1. MRI scan following contrast injection of an FCI hydroxyapatite orbital implant 10 months following primary implantation. Axial (a) and coronal (b) views show diffuse, inhomogeneous enhancement. 


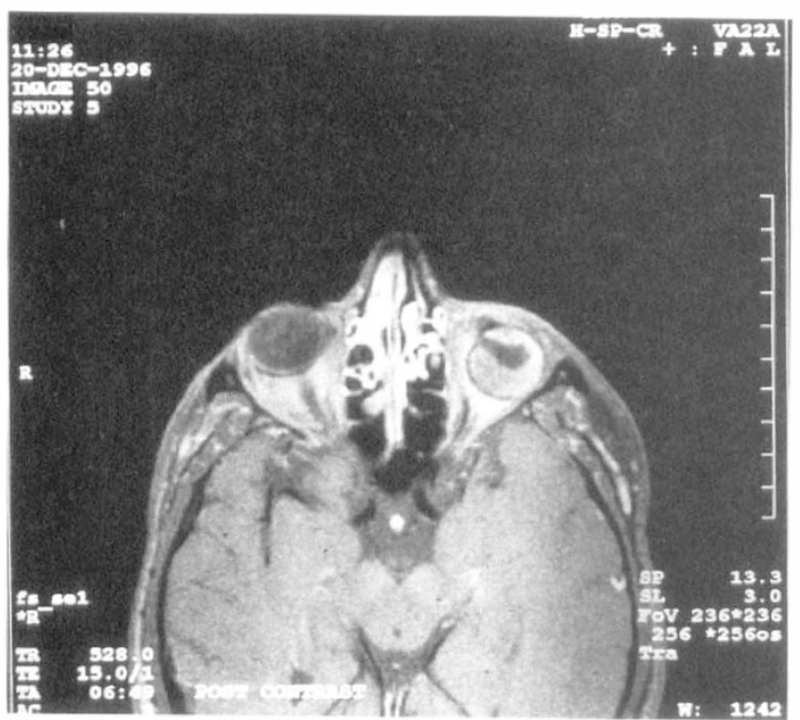

(a)

Fig. 2. MRI scan following contrast injection of an $\mathrm{FCI}$ hydroxyapatite orbital implant 9 months following secondary implantation. Axial (a) and coronal (b) views show a large area of non-enhancement centrally, extending medially.

scanner (Siemens, Erlangen, Germany) using the head coil. The position of the hydroxyapatite implant and enhancement after contrast injection were noted.

\section{Results}

Six male patients and 6 female patients, ranging in age from 5 to 71 years had synthetic $(\mathrm{FCI})$ hydroxyapatite orbital implants. Six patients had primary orbital implants at the time of enucleation and 6 patients had secondary implants (Table 1). One patient developed marked conjunctival chemosis, requiring temporary suture closure of the lids for 1 week. All 12 patients had good postoperative volume augmentation and implant stability. No

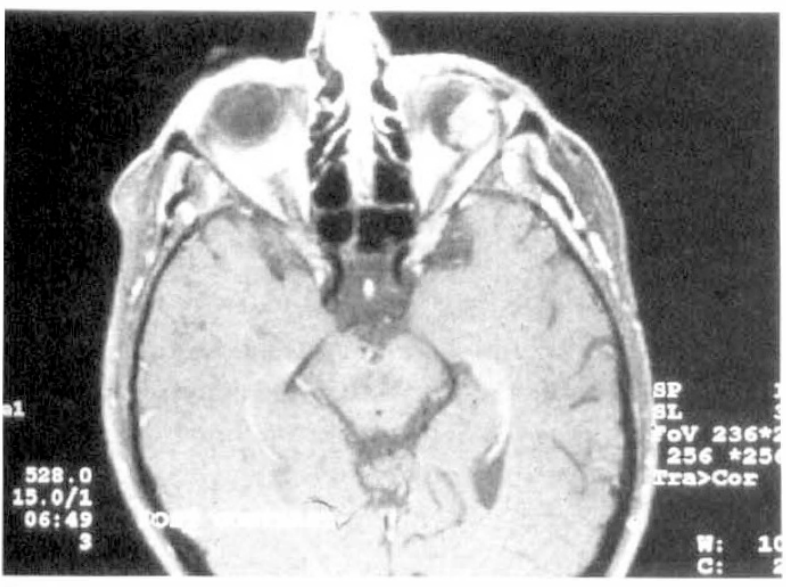

(a)

Fig. 3. MRI scan following contrast injection of an FCI hydroxyapatite orbital implant 9 months following secondary implantation. Axial (a) and coronal (b) views show a large area of non-enhancement in the periphery of the implant.

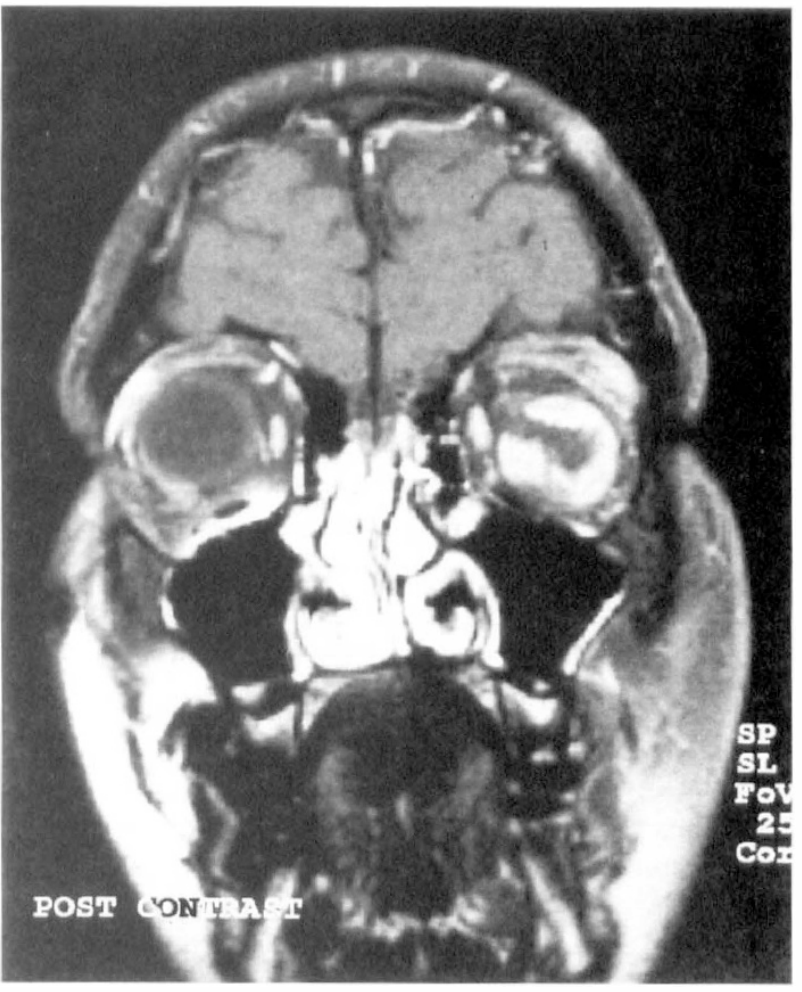

(b)

implant exposures occurred. All patients were satisfied with the cosmetic result of surgery. No patient requested drilling and pegging. Two patients failed to attend for their MRI scan and MRI was contraindicated in 2 patients due to the presence of metal in the orbit or sinus. Therefore, MRI was carried out in 8 patients.

MRI with intravenous gadolinium, using coronal and axial views, demonstrated diffuse inhomogeneous (nonuniform) enhancement in 3 of the primary orbital implants (Fig. 1). One patient with a primary implant had a large area of poor enhancement posteromedially. Moderate to large areas of non-enhancement occurred in all the patients in the secondary implantation group. The extent and site of those areas were variable (Figs. 2, 3).

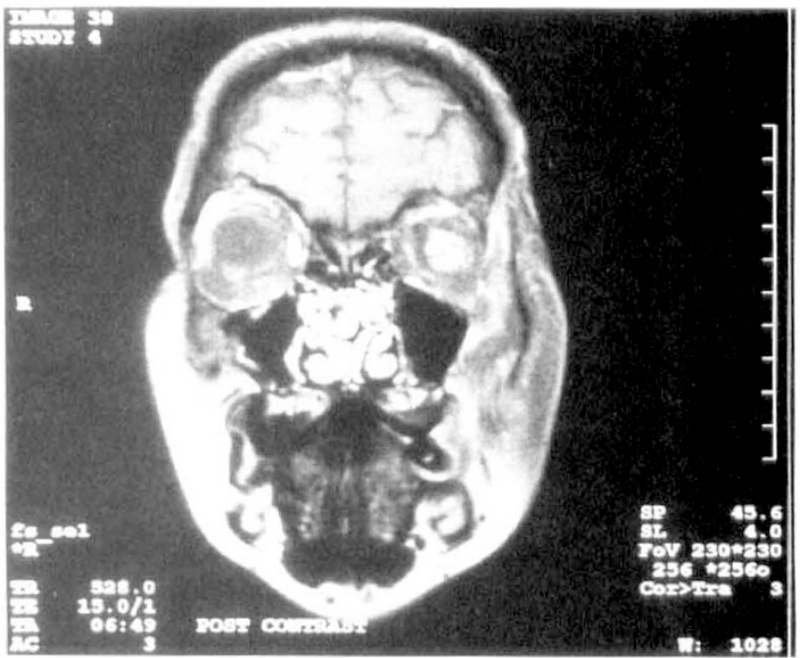

(b) 


\section{Discussion}

Synthetic FCI hydroxyapatite orbital implants are less expensive than the coral hydroxyapatite implant and are thought to be a satisfactory alternative. The synthetic orbital implants have been reported to give good homogeneous vascularisation within 4 months of surgery. ${ }^{8}$ Some surgeons assume vascularisation of these implants after 6-9 months and are happy to drill and peg the implants without prior MRI scanning. In our small consecutive series of 12 patients, all had good clinical results with the synthetic implant and no patient requested drilling with peg insertion. However, in 5 of 8 patients MRI scanning with gadolinium revealed moderate to large areas of poor enhancement within the implant more than 9 months after implantation. MRI scanning with intravenous gadolinium is considered to be a good non-invasive method for evaluating vascularisation of hydroxyapatite implants. It is considered superior to technetium bone scanning, CT, colour Doppler imaging and B-mode ultrasonography. ${ }^{6,7}$

Patients in this study were scanned irrespective of the likelihood of drilling and peg insertion. Although the clinical results were excellent, the very variable vascularisation of these implants was disappointing. It is not clear from this study why a greater percentage of the patients who had secondary implants had significant areas of poor vascularisation. Vascular changes occurring in the orbit following previous enucleation and differences in surgery (more difficulty isolating recti muscles in secondary implantation) may contribute to this. However, one patient in the primary implantation group had a large area of poor vascularisation. We therefore feel that it is more likely that poor vascularisation is occurring secondary to poor interconnecting pores within the implant. A larger series may show no difference between the primary and secondary hydroxyapatite implant vascularisation.
We consider it less than desirable to drill and insert a peg into avascular areas of implants. This could result in infection of the implant due to stagnant fluid collection in avascular areas. We therefore recommend a degree of caution if pegging is planned in implants with significant areas of poor implant vascularisation.

Our study does not support the claims of rapid total vascularisation of synthetic (FCI) hydroxyapatite orbital implants. We recommend MRI with gadolinium prior to drilling and pegging these implants. If complications arise as a result of drilling, it may then be possible to correlate the complications with the vascularisation of the implants.

\section{References}

1. Perry AC. Integrated orbital implants. Adv Ophthalmic Plast Reconstr Surg 1988;8:75-81.

2. Dutton JD. Coralline hydroxyapatite as an ocular implant. Ophthalmology 1991;98:370-7.

3. Ashworth JL, Rhatigan M, Sampath R, Brammar R, Sunderland S, Leatherbarrow B. The hydroxyapatite orbital implant: a prospective study. Eye 1996;10:29-37.

4. Shields CL, Shields J, Eagle RC, De Potter P. Histopathologic evidence of fibrovascular ingrowth four weeks after placement of the hydroxyapatite orbital implant. Am J Ophthalmol 1991;111:363-6.

5. Ferrone PJ, Dutton JJ. Rate of vascularisation of coralline hydroxyapatite ocular implants. Ophthalmology 1992;99:3769.

6. Jamell GA, Hollsten DA, Hawes MJ, Griffin DJ, Klingensmith $\mathrm{WC}$, White WL, et al. Magnetic resonance imaging versus bone scan for assessment of vascularisation of the hydroxyapatite orbital implant. Ophthalmic Plast Reconstr Surg 1996;12:127-30.

7. De Potter P, Shields CL, Shields JA, Flanders AE, Rao VM Role of magnetic resonance imaging in the evaluation of the hydroxyapatite orbital implant. Ophthalmology 1992;99:82430.

8. Rosier Diallo L, Baudchon P, Le Rebeller MJ. Nouveaux implants intra-orbitaires en hydroxyapatite: premiers resultats cliniques. Ophtalmologie 1993;7:435-9. 